\title{
60/70: DA PARTICIPAÇÃO AO COMPORTAMENTAL
}

http:/ / dx.doi.org/10.11606/issn.2237-1184.v0i29p105-114

Celso Favaretto

Universidade de São Paulo (USP)

\section{RESUMO}

No período 1965-68, ocorreu uma reconfiguração das relações entre arte e política, resultante do tensionamento das proposições em curso entre radicalidade experimental e significação política. A categoria de participação, que já adquirira especial relevo nas atividades artísticas, passou a admitir o aspecto comportamental, a corporalidade, como constitutivo dessa nova posição estética. A eficácia política de tal mudança estendeu-se até meados da década seguinte, no horizonte das variadas atividades contraculturais, apesar da pressão e censura agravadas pelo AI-5.

\section{ABSTRACT}

In the period 1965-68, there was a reconfiguration of the relations between art and politics, resulting from the tensioning of the propositions underway between experimental radicality and political signification. The category of participation, which had alread acquired special importance in artistic activities, began to admit the behavioral aspect, corporality, as constitutive of this new aesthetic position. The political efficay of such a change extended until the middle of the following decade, on the horizon of the various counter-cultural activities, in despite of the repression and censorship aggravated by the AI-5.

\section{PALAVRAS-CHAVE:}

Arte;

política;

experimentação artística;

participação;

comportamento;

contracultura.

\section{KEYWORDS}

Art;

politics;

artistic experimentation;

participation;

behavior;

counter-culture. 
s acontecimentos artístico-culturais surgidos entre 1965 e 1968 mobilizaram imagens cheias de paixão, fervor e radicalidade; efeitos de ações que de maneira exemplar realizaram a exigência crítica, o imperativo daquele momento histórico: o imbricamento de experimentação e participação política cujos efeitos se estenderam até meados dos anos 70 . Esta visada permite apreender o fundamental das atividades: a reconfiguração das posições artísticas e críticas que tensionaram e produziram profundas transformações nos modos de entender a relação entre arte e sociedade. A irrupção cultural desses anos incorporou nas artes os sinais que colocaram em questão os discursos instituídos sobre a possível eficácia das artes com a crítica das polarizações dos processos culturais que visavam a provocar, nas canções, nos espetáculos teatrais, nos filmes e nas expressões plásticas o levantamento dos recalques históricos e estéticos, a travessia das forças excêntricas em conflito.

Em resumo: de um lado, as manifestações centradas nos efeitos de denúncia e exortação, especialmente nas canções e em algumas encenações que, utópicas, acreditavam no valor mobilizador da arte como eficaz na realização de expectativas de emancipação social; de outro lado, as proposições que, descrendo desse poder da arte, embora não excluindo o interesse crítico de suas produções, valorizavam a ambivalência crítica das ações, como foi o caso de variadas e diferenciadas atividades assimiladas sob a denominação genérica de tropicalismo. Essas posições definiram compreensões diversas, até em oposição, da necessidade, imperiosa naquele tempo, de participação. A análise das diferenças explicita o conflito das interpretações da realidade brasileira responsáveis pelo tensionamento da significação política das atividades culturais e da produção artística dos anos 60 no Brasil.

Importante nesses acontecimentos, e nem sempre valorizado nas análises do período, foi o fato de que nas experimentações artísticas o corpo se torna personagem conceitual. Sintoma das derivas críticas que surgiam, tal fato indicava que uma outra experiência, a comportamental, estava configurando as tensas relações entre arte e política. Esta nova experiência teve nos anos 1967-68 o seu ponto de definição, e nos anos seguintes adquiriu outras figurações, inclusive com desdobramentos originais a partir de 1969 das experiências contraculturais que propunham uma "nova consciência" e uma "nova sensibilidade" como uma espécie de ultrapassamento, não superação, das posições que, embora comprometidas com a emancipação social, eram antagônicas nos modos de conceber tanto a liberação pessoal como a libertação social. Emblematizados nas palavras-signos "desbunde" 
e "curtição", os comportamentos contraculturais funcionavam como imagens mobilizadoras de uma vida liberada sob o signo da disponibilidade e do prazer, livre do que se supunham serem as limitações da razão ocidental com seus efeitos sobretudo na cultura, nos valores, nas regras e costumes morais instituídos pelas instituições sociais. ${ }^{1}$ As atividades contraculturais foram adquirindo espaço nos rastros das ideias, e atividades tropicalistas, inclusive amplificadas pela circulação de informações que chegavam ao país, referidas às experiências contraculturais do underground norte-americano e pela divulgação de obras erigidas em referência dos novos comportamentos, como Eros e civilização de Herbert Marcuse, Vida contra a morte de Norman Brown e obras de Wilhelm Reich, e muitas dessas ideias aqui disseminadas por jornais e revistas contraculturais, destacando-se nelas os textos de Luiz Carlos Maciel na coluna Undergorund e no encarte Flor do Mal do Pasquim e em revistas marcantes, como Presença, Rolling Stone, Verbo Encantado, O Bondinho, entre outras, disseminadas especialmente no eixo Salvador-Rio. Também, tais desdobramentos vieram nos rastros dos desenvolvimentos recentes no Brasil da psicanálise e de variadas terapias corporais ou de grupo pela difusão do interesse por práticas de expressão corporal, pela acupuntura, com a disseminação das experiências com drogas, do rock, da renovação dos costumes e práticas das relações pessoais e da sexualidade aberta assim como a valorização das religiosidades e rituais orientais e dos sincréticos afro-brasileiros.

O núcleo das transformações artísticas e comportamentais estava na explicitação da conjugação de arte e vida, processo que vinha informando as artes desde o romantismo, com ênfase no rimbaudiano desregramento de todos os sentidos como visionária recuperação de uma suposta unidade humana que teria sido perdida pela ação do "racionalismo" da cultura ocidental. Aqui e ali, entretanto, em algumas dessas manifestações, não se excluía, ainda que visionariamente, uma outra imagem do político, agora siderado pelas mudanças dos comportamentos. Walter Benjamin, como se sabe, ao pensar o sentido político do surrealismo - em que se ensaiava, com a admissão do inconsciente nas ações políticas e nas artes, a valorização do corpo -, considerou que a conjugação desses fatores na relação de arte e vida aparecia como exigência na atitude de capturar as forças do êxtase para a revolução. Aliás, proposição muito apropriada para se entender algumas das propostas artísticas no Brasil, as tropicalistas, em que o corpo aparecia como desviante político. ${ }^{2}$

\footnotetext{
1 FAVARETTO, Celso. "A contracultura, entre a curtição e o experimental”. In: MODOS - Revista de História da Arte, v. 1, n. 3, set-dez 2017.

2 CÁMARA, Mario. Corpos pagãos- usos e figurações na cultura brasileira (1960-1980). Trad. Luciana di Leone. Belo Horizonte: Editora UFMG, 2014, p. 9.
} 
Assim, este arco de atividades em que se dava a intersecção ou a justaposição de ideias e comportamentos renovados, ressaltava a necessidade, que se impunha como necessidade histórica, de fazer a crítica da "realidade brasileira" e de articular a resistência política face às restrições do regime militar. Tratava-se de levar adiante, agora em condições específicas determinadas pelo golpe civil-militar, o trabalho de renovação que vinha impulsionando o desejo de modernidade artístico-cultural, desde a década de 1950. No notável ano de 1967 apareceram: o filme Terra em transe, de Glauber Rocha; as encenações de $O$ rei da vela de Oswald de Andrade no Teatro Oficina; o projeto ambiental Tropicália, de Hélio Oiticica, instalado na exposição Nova objetividade brasileira; a música tropicalista do Grupo Baiano e o livro PanAmérica de José Agrippino de Paula - e em outra direção, as canções ditas de protesto e as encenações de Augusto Boal no Teatro de Arena em Arena conta Tiradentes. É importante acentuar que, se havia uma espécie de unanimidade quanto à compreensão da necessidade de resistência à ditadura, as propostas e ações distinguiam-se quanto aos modos de articular a significação política, nas estratégias específicas que articulavam experimentação e participação, engajamento e desmistificação das ilusões quanto aos poderes da arte.

No amplo espectro dessas atividades, entre 65 e 69, artistas plásticos - como entre outros Nelson Leirner, Marcelo Nitsche, Rubens Gerchman, Antonio Dias, Carlos Vergara, Roberto Magalhães, Hélio Oiticica, Lygia Clark, Lygia Pape, Antonio Manuel -, efetuaram de modos diversos a passagem da obra ao objeto, às ambientações, acontecimentos, ressaltando com ênfase crescente a corporeidade como elemento intrínseco à tônica processual e conceitual em evidência em toda a arte contemporânea. Nas encenações de José Celso Martinez Correa, O rei da vela, Roda viva (68) e em $\mathrm{Na}$ selva da cidade (69), a violência da arte articulava táticas visando a mudanças na eficácia política do teatro, rompendo as ligações costumeiras com o público, violentando-o: um teatro da crueldade e da agressão, do absurdo brasileiro; teatro anárquico, cruel, da grossura; das sensações, do prazer e da dor. As encenações do Teatro de Arena, comprometidas com formas de arte engajada, em que a participação política era pensada de modo a obter efeitos de conscientização pela tematização política de questões que totalizavam a realidade brasileira, eram afirmativas, propunham a atitude "sempre de pé" como o horizonte em que a participação provinha da transferência de símbolos históricos e culturais de resistência visando a uma tomada de posição face às questões políticas e sociais imediatas. As canções tropicalistas incorporaram voluntariamente, nos temas, nas formas, procedimentos e linguagens, ritualização, gestualidade, corpo e teatralidade - cuja expressão mais contundente esteve nos programas de TV Divino maravilhoso - compondo uma atitude que articulava "o conceitual e o fenômeno vivo", na formulação de Hélio 
Oiticica; renovação técnica e de comportamento, em que o político não estava ausente, frequentemente de modo indireto, explorando ou induzindo a novas formas de subjetividade.

Não é descabido se dizer que nessas produções pela primeira vez se evidencia efeitos de um regime estético que, salientando o processo de "incorporação", produzia imagens daquela descolonização visada nos projetos de resistência. Um processo, aliás, que se estendeu até meados de 70, no âmbito das experiências contraculturais ou alternativas. Nelas, a oposição à situação instalada pelo regime militar não se fazia explicitamente, antes estava no gesto subversivo, mescla de candidez e insolência, de aposta na eficácia do gesto articulado à atitude básica de desestetização da arte e, frequentemente, de estetização da vida, vale dizer, dos comportamentos. ${ }^{3}$

Hélio Oiticica foi quem melhor explicitou naquela ocasião, nas suas proposições artísticas e nos escritos, a emergência do corpo nas produções daquele tempo, o interesse dos artistas em "transformar os processos de arte em sensações de vida". ${ }^{4}$ Proposição comum aos deslocamentos operados nas artes da modernidade, é uma consequência da inscrição do corpo na arte, da vida como processo criador, com que se acede a uma outra ordem do simbólico. Nesta arte, o corpo não é mero protagonista, como lugar da sensorialidade, antes uma estrutura-comportamento que redimensiona o sensível da arte. A consequente requalificação estética, que rompe a demarcação entre arte e vida, decorre da percepção do corpo humano na vida cotidiana, assim como do seu poder de afetar, constituindo-se a partir de então em condição indispensável da experiência artística. Este processo, ao mesmo tempo vivencial e cultural, ratifica o fato de que em muitos artistas modernos a variação intensiva dos afetos é atividade constitutiva do sujeito. Aí situa-se também a resistência dessa arte, em que ela é política: pela circulação, mobilidade, fuga, difusão de comportamento singulares - o contrário da "tomada de consciência" que foi o objetivo de grande parte da produção artística "engajada" durante toda a década. Assim, as proposições desses artistas dos anos 67-68 incluem-se no processo em curso de transformação radical da concepção de artista - que se tornou um motivador para a criação. Criar, advertiu Oiticica, citando Yoko Ono, "não é tarefa do artista, sua tarefa é a de mudar o valor das coisas". ${ }^{5}$ Oiticica apontava assim, junto com outros artistas, para uma nova inscrição do estético: a arte como intervenção cultural, em

\footnotetext{
${ }^{3}$ Este texto retoma, sob este aspecto, com modificações, "Incorporação: corpo e política nos anos 60/70". In: FREITAS, Artur et al. (orgs). Imagem, narrativa e subversão. São Paulo: Intermeios, 2016. ${ }^{4}$ OITICICA, Hélio. Catálogo da Whitechapel Experience. Londres, 1969 reproduzido na coletânea de textos Aspiro ao Grande Labirinto (org. de Luciano Figueiredo, Lygia Pape, Waly Salomão). Rio de Janeiro: Rocco, 1986.

${ }^{5}$ OITICICA, Hélio. “Experimentar o experimental”. In: ARAÚJO NETO, Torquato Pereira de; SALOMÃO, Waly Dias (orgs.). Navilouca. Rio de Janeiro: Edições Gernasa, 1974.
} 
que o campo de ação é a atividade coletiva que intercepta subjetividade e significação social.

Nesta direção, a da experimentação que acentua a incorporação, na literatura o destaque fica por conta do singular livro de José Agrippino de Paula, PanAmérica. ${ }^{6}$ Nele circulam as fantasmagorias da sociedade do espetáculo, os estilhaços da cultura e do imaginário do consumo, encenação, em que se observa a volatização do simbólico, a corrosão das identidades, a reificação do desejo nas obsessões eróticas e na pornografia. $\mathrm{O}$ que também aparecia com a mesma radicalidade em Rito do amor selvagem de 1969. No prefácio da reedição em 2001, Caetano Veloso lembra o impacto do livro antes do aparecimento de suas canções tropicalistas uma informação importante, pois esclarece ainda mais a concomitância do procedimento de incorporação nas produções que foram identificadas como tropicalistas, na música, no teatro e na literatura e, um pouco depois, no cinema dito marginal e no horizonte das experiências contraculturais. Com efeito, é evidente a sintonia entre o modo de enunciação em muitas dessas canções, a narrativa de Agrippino, as imagens visuais de artistas da Nova Figuração, particularmente de Antonio Dias, a canção de Caetano Veloso e a "Tropicália" de Oiticica. As semelhanças são estruturais, de linguagem e operação de descentramento cultural: construtivistas e dessacralizantes, elas recolocam as relações entre fruição estética e crítica social fora dos parâmetros fixados pela oposição entre experimentalismo e participação, enfatizando não os temas, mas os processos e procedimentos. Opõe-se assim, em outra direção, ao outro importante romance de 1968: Quarup, de Antonio Callado, modelo da literatura participante, que enfatiza o poder da arte na conscientização política como contribuição para efeitos de realização de utopias de transformação social. ${ }^{7}$

Já em 1965 o aparecimento de Lugar Público ${ }^{8}$, o primeiro romance de Agrippino, foi surpreendente, pois destoava das temáticas técnicas usuais. Pintando uma paisagem cultural em que se notam ressonâncias da literatura existencialista e ecos da beat generation, do cinema americano e italiano em circulação nos meios intelectuais e artísticos sintonizados com o desejo de modernidade. A narrativa flui ininterruptamente, sem divisão de capítulos e figurando aspectos fragmentários da banalidade do cotidiano moderno na cidade de São Paulo. Insipidez, maquinismo, velocidade, multidões, anúncios, cinema, mitologias da cultura de massa são índices

\footnotetext{
6 PAULA, José Agrippino de - PanAmérica. Rio de Janeiro-GB: Tridente, julho de1967. Capa de Antônio Dias. Texto de capa de Mário Schenberg. 2a. Ed. São Paulo: Max limonad, 1988; $3^{\text {a }}$. Ed. São Paulo: Papagaio, 2001.

7 CALADO, Antonio. Quarup. Rio de Janeiro: Civilização brasileira, 1968.

8 PAULA, José Agrippino de. Lugar público. Rio de Janeiro: Civilização brasileira, 1965. Texto de capa de Carlos Heitor Cony. 2a . Ed. São Paulo: Papagaio, 2004.
} 
da cultura urbana da sociedade industrial, que reapareceriam em PanAmérica, e que compõem uma narrativa sem história, dessubjetivada.

Entretanto, se Lugar Público é um romance em que ainda se reconhecem elementos da profundidade, embora não psicológica, da narrativa moderna, PanAmérica não é um romance; o livro é assim designado pelo autor: "epopeia de José Agrippino de Paiva". Apresenta características comuns às vanguardas, próximas das tropicalistas, como uma experiência isolada de ficção no Brasil, cuja contundência provém em grande parte de ter dado à mistura de referências culturais um corpo sensível tão emblemático quanto o das canções tropicalistas e o de vários artistas plásticos. Não é à toa que a capa da primeira edição é de Antônio Dias, ilustrada com uma imagem dos seus violentos quadros narrativos no quadro da Nova Figuração. Texto delirante que finge um efeito de real, a epopeia de Agrippino funciona como uma alucinação, uma fantasmagoria toda feita de cacos, de "estilhaços da cultura". 9 Blocos narrativos descontínuos se sucedem, construindo hipérboles de aspectos das mitologias contemporâneas: sexualidade, luta política, astros cinematográficos, personagens dos esportes, da política, são agenciados numa narrativa despsicologizada e descentrada, irredutível a um painel ou a uma imagem totalizadora. Procedendo por via expositiva, indiciada pelo uso reiterado da conjunção e o campo onde a narrativa se institui é fragmentário e lacunar. As referências e fragmentos da cultura são articulados em ritmo cinematográfico, com cortes e fusões. Escrita tóxica, violenta, com o excesso de imagens e reiteração dos mesmos elementos, induz o leitor à desvalorização dos objetos designados, com que se dá a destruição da própria imagem. Assim, pulverizando os códigos de produção e recepção, reiterando o visível, hiperbolizando a representação, o texto desmobiliza as expectativas do leitor que nele procuraria um sentido, uma significação profunda, uma crítica. Exterioridade pura, a narrativa corrói o sujeito da representação. $\mathrm{O}$ eu reiterado que o narrador dissemina no texto não fixa nenhuma identidade, antes a pulveriza. Não sendo posição de um sujeito, o eu é apenas um efeito enunciativo submetido a um regime técnico, homólogo ao da narrativa cinematográfica. Máquina histérica, a enunciação é ritmada pela repetição, o que pode ser associado à forma industrial da produção cinematográfica.

Epopeia contemporânea do império americano, como disse Mário Schenberg na apresentação da primeira edição, o livro tematiza mitologias da cultura da sociedade industrial. Nesta narrativa ciclópica, os tipos gerados pela indústria cinematográfica de Hollywood são apresentados como naturais, quando são, na verdade, convencionais. Astros e estrelas,

\footnotetext{
${ }^{9}$ HOISEL, Evelina. Supercaos, os estilhaços da cultura em PanAmérica e Nações Unidas. Rio de Janeiro: Civilização brasileira, 1980.
} 
intercalados pela aparição de políticos, esportistas e outros personagens, entram na cena e dela saem, sem nada que justifique ou requeira propriamente uma ação. Os atos e gestos que desenvolvem são típicos, indiciando emblemas do imaginário imperialista. O narrador, nem herói, nem anti-herói, vaga por entre camas e outros cenários cinematográficos, às vezes como um herói, logo desmentido, que quer destruir o império, destruindo o gigante Joe Di Maggio e conquistando a bela Afrodite, Marylin Monroe, personagem-ícone de Agrippino. Tomando a forma de uma superprodução hollywoodiana, como Os Dez Mandamentos de Cecil B. de Mille, outro ícone, reconstruindo detalhes das filmagens, cenários, processos e técnicas, expõe a produção da ilusão, como se fosse o desenvolvimento de uma construção romanesca, que configurasse a epopeia de conquista e destruição do grande império do norte. Mas as encenações cinematográficas com as constelações do império são alternadas com outras encenações, como que abastardando as referências: são as cenas da outra América, que não se submete aos planos de uma operação panamericana, referência clara à política norte-americana de intervenção em alguns países, sob a capa de uma operação pela paz, na verdade de dominação, disfarçada de luta contra a propalada influência comunista. Na epopeia, a única possibilidade de resistência é a guerrilha, pois forma política atópica, desterritorializada, a única que age, não com a força, mas com astúcia.

A referência à situação histórica brasileira é óbvia, alegoricamente tratada. O golpe de 1964, as passeatas, a repressão do governo militar, o aparecimento da guerrilha urbana, o clima de terror, a identificação da resistência ao regime com o Partido Comunista, são alguns dos índices. Mas há outros, culturais, como o índio brasileiro, na vitrine de uma cidade americana, nu, enfeitado de penas e com o enorme e mole pênis que caía até o joelho, portanto exangue, desenergizado à custa da exploração. Este objeto exótico, imagem brasileira pronta para exportação e consumo, é um raro signo motivado da narrativa, a única manifestação, salvo engano, de um sujeito historicamente afirmado: "eu sofria internamente, (...) gritei de ódio". Acoplado às referências brasileiras, percebe-se que, intencionalmente, a guerrilha estende-se para toda a América do Sul e Central, indiciando-se nisto o despertar da solidariedade latinoamericana, significada principalmente na figura exemplar de Che Guevara.

Na apresentação de Rito do Amor Selvagem, em 1969, - encenação multimídia inovadora, concebidas por ele e Maria Esther Stokler, a partir de alguns fragmentos da peça Nações Unidas escrita em 1966, ainda inédita - Agrippino caracteriza o processo de composição do texto e da encenação como mixagem, por analogia com o que no cinema é a mistura de várias faixas de som, diálogos, ruídos e música; nele a mistura dos meios, de diversas mídias, articulam informações, fragmentos, na simultaneidade. A 
falta de fé no poder da palavra, diz ele, levou-o ao que denominou "texto de desgaste", todo calcado nos estereótipos, restos e cacos da cultura de consumo, significantes-objetos industriais prontos para a circulação, em que o desejo é reificado. É o mesmo processo da composição de PanAmérica, em que uma ritualização sem fundo fixa como realidade a simples aparência, substituindo os valores simbólicos da cultura e a profundidade da experiência interior das tramas romanescas em pura exterioridade de acontecimentos que viram ícones ou emblemas. ${ }^{10}$

Assim, a atitude configurada, nas produções aqui tomadas como exemplares, além de conjugar a reversão artística e o interesse político, enfim as dimensões ética e estética, as transformações da arte, a renovação da sensibilidade e a participação coletiva, implicava o redimensionamento cultural dos protagonistas das ações. As proposições visavam a liberar as atividades do ilusionismo, para que as ações funcionassem como intervenção nos debates daquele tempo. De modo que, o campo de ação das atividades não se reduzia à crítica do sistema da arte: inscrevia-se como uma atividade coletiva, visionária, em que se interceptavam a produção de novas subjetividades e a significação social das ações. Portanto, a dessestetização processada nesses âmbitos para comportamentos não significava uma valorização simples das sensações e dos afetos como oposição ao suposto e genérico racionalismo atribuído aos modos de compreender as significações assumidas na arte no Ocidente moderno. Visava, antes, ao devir da experiência, em que a totalização do vivido levaria necessariamente à transmutação das relações entre arte e vida e, portanto, dos indivíduos, através da transformação da arte em atividade cultural, por efeito da multiplicação e da "expansão celular". Aí, nos acontecimentos da vida "como manifestação criadora", brilharia o esplendor do sentido, encarnado em situações, indivíduos, processos e comportamentos que desbordariam das regras institucionadas do viver-em-sociedade, em favor de um viver-coletivo. Conceituais e sensoriais, esses acontecimentos materializariam uma imagem do pensamento e da existência que valorizariam situações instáveis e indeterminadas, de fim impreciso, típicas das experiências exemplares, simbólicas, nas quais coexistem intensidade de sentido, convicção e violência: transformabilidade. ${ }^{11}$

\footnotetext{
10 FAVARETTO, Celso. “A outra América". In: Jornal de Resenhas, n. 75, 09/06/2001. Reproduzido em: NASCIMENTO, Milton do (org.) - Jornal de Resenhas, v. III. São Paulo: Discurso editorial, 2002, pp. 2155-7.

${ }^{11}$ Idem. "60/70: viver a arte, inventar a vida". In: LAGNADO, Lisette (org.). 27a. Bienal de São

Paulo: Seminários. Rio de Janeiro: Cobogó, 2008, p. 240-9.
} 
Celso Fernando Favaretto é doutor (1988) em Filosofia pela FFLCH da USP, área de Estética. Livre-docente (2004) pela Faculdade de Educação da USP. Atualmente, é professor-associado aposentado atuando no Programa de Pós-Graduação em Educação da FE-USP e no Programa de Pós-Graduação em Filosofia da Faculdade de Filosofia, Letras e Ciências Humanas da USP. Autor dos livros Tropicália, Alegoria Alegria (1979; $4^{a}$ edição, 2008) e de A Invenção de Hélio Oiticica (1992; $2^{\mathrm{a}}$ edição, 2000; reimpressão, 2015). Foi membro fundador e coordenador do Centro de Estudos de Arte Contemporânea e da revista Arte em Revista (1979-1985). Contato: $\underline{\text { fffavare@usp.br }}$ 